\title{
Multiscale systematic risk
}

\author{
Ramazan Gençay $^{\mathrm{a}, *}$, Faruk Selçuk ${ }^{\mathrm{b}}$, \\ Brandon Whitcher ${ }^{\mathrm{c}}$ \\ ${ }^{a}$ Department of Economics, Simon Fraser University, 8888 University Drive, Burnaby, \\ British Columbia V5A 1S6, Canada \\ ${ }^{\mathrm{b}}$ Department of Economics, Bilkent University, Bilkent, 06800 Ankara, Turkey \\ ${ }^{\mathrm{c}}$ Translational Medicine \& Technology, GlaxoSmithKline, Greenford UB6 OHE, UK
}

\begin{abstract}
In this paper we propose a new approach to estimating systematic risk (the beta of an asset). The proposed method is based on a wavelet multiscaling approach that decomposes a given time series on a scale-by-scale basis. The empirical results from different economies show that the relationship between the return of a portfolio and its beta becomes stronger as the wavelet scale increases. Therefore, the predictions of the CAPM model should be investigated considering the multiscale nature of risk and return.
\end{abstract}

(c) 2004 Elsevier Ltd. All rights reserved.

JEL classification: $\mathrm{G} 0 ; \mathrm{G} 1$

Keywords: Systematic risk; Scaling; Wavelets; Beta estimation; Multiresolution analysis

\section{Introduction}

The Capital Asset Pricing Model (CAPM) of Sharpe (1964) and Lintner (1965) has received considerable attention in financial studies. ${ }^{1}$ In its simplest form, the

\footnotetext{
* Corresponding author.

E-mail addresses: gencay@sfu.ca (R. Gençay),faruk@bilkent.edu.tr (F. Selçuk),brandon.j.whitcher@ gsk.com (B. Whitcher).

${ }^{1}$ As of February 2002, a keyword search of "CAPM" in the Journal of Economic Literature (JEL) database returned 411 articles while the keyword "systematic risk" resulted in 311 articles.
} 
CAPM predicts that the excess return of a stock (return over the riskless rate of return) should be proportional to the market premium (market return over the riskless rate of return). The proportionality factor is known as the "systematic risk" or the "beta" of an asset. ${ }^{2}$

Early empirical studies on the CAPM such as Black et al. (1972) and Fama and MacBeth (1973) were supportive of the implications of the model. That is, the average return of high beta stocks was higher than the average return of low beta stocks. Furthermore, the relationship was roughly linear, although the slope was too flat to strongly support the CAPM (Campbell, 2000). Later studies focused on beta estimation issues in detail. Some examples of the concerns on beta estimation are as follows: the stability of beta over time (Harvey, 1989), borrowing constraints (Black, 1972), the impact of structural change and regime switches (Garcia and Ghysels, 1998), the effect of world markets and volatility (Bekaert and Harvey, 1995, 1997; Harvey, 1991), non-synchronous data issues (Scholes and Williams, 1977), time horizons of investors (Levhari and Levy, 1977) and the impact of the return interval (Brailsford and Josev, 1997; Brailsford and Faff, 1997; Cohen, et al., 1986; Frankfurter, et al., 1994; Hawawini, 1983; Handa, et al., 1989, 1993).

Studies on the impact of the return interval of beta estimates point out the importance of the time scale issue. An early study by Levhari and Levy (1977) showed that if the analyst used a time horizon shorter than the true one ${ }^{3}$, the beta estimates were biased. Fama $(1980,1981)$ provided evidence that the power of macroeconomic variables in explaining the stock prices increased with increasing time length. Handa et al. (1989) reported that different beta estimates were possible for the same stock if different return intervals were considered. Similarly, Handa et al. (1993) rejected the CAPM when monthly returns were used but failed to reject the CAPM if the yearly return interval was employed. Cohen et al. (1986) and references therein provided ample evidence that the beta estimates were sensitive to return intervals. By using Australian equity market data, Brailsford and Faff (1997b) reported that the CAPM (with a GARCH-M specification) was supported for weekly and monthly interval returns while the greatest support was found in the weekly return intervals. The daily return interval in that study did not support the CAPM. Hawawini (1983) proposed a model to overcome the interval effect in beta estimation.

In this paper, we propose a new approach to estimating systematic risk (the beta) in a CAPM. The proposed method is based on wavelet analysis that enables us to decompose a time series, measured at the highest possible frequency, into different time scales. It provides a natural platform on which to investigate the beta behavior (systematic risk) at different time horizons without losing any information. The empirical results from different economies show that the relationship between the return of a portfolio and its beta becomes stronger as the scale increases. Therefore,

\footnotetext{
${ }^{2}$ See Campbell (2000) and Cochrane (1999) for a survey of the recent developments in the finance literature in general and asset pricing in particular.

${ }^{3}$ The "true" time horizon is defined as the relevant time horizon implicit in the decision making process of investors.
} 
predictions of the CAPM are more relevant in a multiscale framework as compared to short time horizons.

This paper is structured as follows. The CAPM model is presented in Section 2. Wavelet analysis, the wavelet variance and the wavelet covariance are presented in Section 3. Multiscale beta estimation with S\&P 500 stocks in the United States, Financial Times Stock Index (FTSE) stocks in the United Kingdom and DAX stocks in Germany is studied in Section 4. We conclude afterwards.

\section{Capital asset pricing model (CAPM)}

The capital asset pricing model (CAPM) naturally arises from the utility maximization problem of a representative agent. ${ }^{4}$ Consider a consumer with a horizon of $T$ periods who wants to maximize his present discounted value of expected utility

$$
\max E_{0}\left[\sum_{t=0}^{T-1} \frac{1}{(1+\theta)^{t}} U\left(c_{t}\right)\right]
$$

where $E_{0}$ denotes expectation conditional on information at time $0, \theta$ is the subjective rate of time preference, $U(\cdot)$ is the utility function and $c_{t}$ is consumption. Suppose that the consumer can allocate his wealth among $n-1$ risky assets with an $r_{i t}$ rate of return and a riskless asset with a rate of return $r_{0 t}$. The maximization results in $n$ first-order conditions in the following form

$$
U^{\prime}\left(c_{t}\right)=\frac{E\left[U^{\prime}\left(c_{t+1}\right)\left(1+r_{i t}\right)\right]}{1+\theta}, \quad i=0, \ldots, n-1 .
$$

These first-order conditions show that the consumer must choose a consumption path such that the marginal utility of consumption for this period equals the discounted expected marginal utility of the consumption for the next period. The first-order conditions must hold regardless of the characteristics of the assets, whether they are risky or riskless. By rearranging the first-order conditions in Eq. (2),

$$
E\left[U^{\prime}\left(c_{t+1}\right)\left(r_{i t}-r_{0 t}\right)\right]=0, \quad i=1, \ldots, n-1,
$$

which may be rewritten as

$$
E\left[U^{\prime}\left(c_{t+1}\right)\right] E\left[r_{i t}-r_{0 t}\right]+\operatorname{Cov}\left[U^{\prime}\left(c_{t+1}\right), r_{i t}\right]=0, \quad i=1, \ldots, n-1 .
$$

At equilibrium, the return from asset $i$ must satisfy the following equation

$$
E\left(r_{i t}\right)=r_{0 t}-\frac{\operatorname{Cov}\left[U^{\prime}\left(c_{t+1}\right), r_{i t}\right]}{E\left[U^{\prime}\left(c_{t+1}\right)\right]}, \quad i=1, \ldots, n-1 .
$$

\footnotetext{
${ }^{4}$ See Blanchard and Fischer (1989, Ch. 10) and Gençay et al. (2001a, Ch. 3) and Gençay et al. (2001a, Ch. 7).
} 
According to Eq. (5), the investor will invest in an asset with an expected rate of return less than the risk-free rate of return if the asset return has a positive relationship with the marginal utility of consumption. This is because the asset is a hedging tool for consumption smoothing, as it provides a higher rate of return when the marginal utility of consumption is high and a lower rate of return when the marginal utility of consumption is low. ${ }^{5}$

Suppose there exists an asset $m$ such that its return is negatively related with the marginal utility of consumption in the next period, so that $U^{\prime}\left(c_{t+1}\right)=-\gamma r_{m t}$ for some positive $\gamma$. It follows that $\operatorname{Cov}\left[U^{\prime}\left(c_{t+1}\right), r_{i t}\right]=-\gamma \operatorname{Cov}\left(r_{i t}, r_{m t}\right)$. Eq. (5) must hold for asset $m$ as well, such that

$$
E\left(r_{m t}\right)=r_{0 t}-\frac{\operatorname{Cov}\left[U^{\prime}\left(c_{t+1}\right), r_{m t}\right]}{E\left[U^{\prime}\left(c_{t+1}\right)\right]}=r_{0 t}+\frac{\gamma \sigma_{m}^{2}}{E\left[U^{\prime}\left(c_{t+1}\right)\right]},
$$

where $\sigma_{m}^{2}$ is the return variance for asset $m$. It follows that

$$
E\left(r_{i t}\right)=r_{0 t}+\left[\frac{\operatorname{Cov}\left(r_{i t}, r_{m t}\right)}{\sigma_{m}^{2}}\right]\left[E\left(r_{m t}\right)-r_{0 t}\right] .
$$

Notice that the return from asset $m$ is assumed to be negatively correlated with the marginal utility of consumption next period. If we assume that $m$ is a market portfolio (all traded assets in the market), Eq. (7) is known as the security market line in the CAPM of Sharpe (1964) and Lintner (1965). Eq. (7) implies that the excess return from asset $i$ (in excess of the risk-free asset return) should be proportional to the market premium (market return in excess of the risk-free asset return). The proportionality factor is known as systematic risk, or the beta of an asset,

$$
\beta_{i}=\frac{\operatorname{Cov}\left(r_{i t}, r_{m t}\right)}{\sigma_{m}^{2}} .
$$

In empirical finance, the usual estimator for $\beta_{i}$ is the OLS estimate from the following regression

$$
\left(r_{i t}-r_{0 t}\right)=\beta_{i}\left(r_{m t}-r_{0 t}\right)+\epsilon_{i t},
$$

where $\epsilon_{i t}$ is a white noise disturbance term. We now propose an alternative multiscale estimator for the systematic risk or beta of an asset in Eq. (8).

\section{Wavelets}

Wavelet filters provide an easy vehicle in which to study the multiscale properties of a process. It is important to realize that economic/financial time series need not follow the same relationship as a function of time horizon (scale). Hence, a transform that decomposes a process into different time horizons is appealing as it differentiates

\footnotetext{
${ }^{5}$ Because of the diminishing marginal utility assumption, the marginal utility of consumption is high when the level of consumption is low and the marginal utility of consumption is low when the level of consumption is high.
} 
seasonalities, reveals structural breaks and volatility clusters, and identifies local and global dynamic properties of a process at distinct time scales.

With respect to economics and finance, the works of J. B. Ramsey and co-authors first introduced wavelets into the mainstream literature. Ramsey and Zhang (1997) performed a time-frequency analysis of foreign exchange rates using wavelets. They found that wavelet analysis succinctly captured a variety of nonstationary events in the series. Ramsey and Lampart (1998a,b) decomposed economic variables across several wavelet scales in order to identify different relationships between money and income, and between consumption and income. See Ramsey (1999) for a recent review article on wavelets in economics and finance.

Gençay et al. (2001a) presented a general framework for the basic premise of wavelet filtering within the context of economic/financial time series. The authors illustrated that a number of concepts such as nonstationarity, multiresolution and approximate decorrelation emerged from wavelet filters. Wavelet filtering provides a natural platform on which to deal with the time-varying characteristics found in most financial time series, and thus the assumption of stationarity may be avoided. Gençay et al. (2001b) proposed a simple method for intraday seasonality extraction that was free of model selection parameters. Their methodology is based on a wavelet multiscaling approach which decomposes the data into its low- and highfrequency components. Gençay et al. (2001c) investigated the scaling properties of foreign exchange volatility through a multiscale decomposition of the variance and covariance between two time series on a scale-by-scale basis. It was shown that foreign exchange rate volatilities follow different scaling laws at different horizons.

\subsection{Multiscale analysis}

Suppose the economy consists of several agents with different time horizons when it comes to making a consumption-saving decision. Hence, predictions of the CAPM should be investigated at different time scales. Different estimates of beta for the same asset at different return intervals, documented by empirical research, probably reflects this fact. ${ }^{6}$ Wavelet analysis is a natural tool for investigating different time scale properties of beta by decomposing returns on a scale-by-scale basis.

Unlike the Fourier transform, that uses sine and cosine functions on which to project the data, the wavelet transform utilizes a wavelet function that oscillates on a short interval in time. The Haar wavelet is a simple example of a wavelet function that may be used to obtain a multiscale decomposition of a return series. The Haar wavelet filter coefficient vector, of length $L=2$, is given by $h=\left(h_{0}, h_{1}\right)=$ $(1 / \sqrt{2},-1 / \sqrt{2})$. Three basic properties characterize a wavelet filter ${ }^{7}$ :

$$
\sum_{l} h_{l}=0, \quad \sum_{l} h_{l}^{2}=1, \text { and } \sum_{l} h_{l} h_{l+2 n}=0 \text { for all integers } n \neq 0 .
$$

\footnotetext{
${ }^{6}$ Bjornson et al. (1999) investigate the influence of low- and high-frequency macroeconomic forces on asset pricing and show that different frequency dynamics have different effects on the systematic risk.

${ }^{7}$ We are specifically concerned with the Haar and other compactly supported orthogonal wavelets such as those of Daubechies (1992).
} 
That is, the wavelet filter sums to zero, has unit energy, and is orthogonal to its even shifts. These properties are easily verified for the Haar wavelet filter. The first property guarantees that $h$ is associated with a differencing operation and thus identifies changes in the data. The second ensures that the coefficients from the wavelet transform will have the same energy as the data, where energy is defined to be the sum of squares. Thus, neither extra information has been added through the wavelet transform nor has any information been excluded. The third property allows for efficient construction of an orthogonal transform and therefore efficient implementation on a computer. The complementary filter to $h$ is the Haar scaling filter $g=\left(g_{0}, g_{1}\right)=(1 / \sqrt{2}, 1 / \sqrt{2})$, which possesses the following attributes:

$$
\sum_{l} g_{l}=\sqrt{2}, \quad \sum_{l} g_{l}^{2}=1, \text { and } \sum_{l} g_{l} g_{l+2 n}=0 \text { for all integers } n \neq 0 .
$$

The scaling filter follows the same orthonormality properties of the wavelet filter, unit energy and orthogonality to even shifts, but instead of differencing consecutive blocks of observations, the scaling filter averages them. Thus, $g$ may be viewed as a local averaging operator. Additional information regarding wavelet filters, including the Haar and other compactly supported orthogonal wavelets, and their properties may be found in, for example, Mallat (1998) and Gençay et al. (2001a).

The Haar wavelet filter coefficient $h$, when applied to a return series $r_{t}$, produce the following wavelet coefficients

$$
\sqrt{2} \tilde{w}_{1 t}=h_{0} r_{t}+h_{1} r_{t-1}, \quad t=0,1, \ldots, T-1 .
$$

The factor of $\sqrt{2}$ is necessary to guarantee that the squared norm of the wavelet coefficients is equivalent to the squared norm of the return series. We do not reference a particular asset with $r_{t}$ in Eq. (12) in order to simplify notation. Thus, the wavelet coefficient $\tilde{w}_{1 t}$ is a weighted difference between consecutive returns. The Haar scaling filter coefficient vector $g$ is used to produce the scaling coefficients

$$
\sqrt{2} \tilde{v}_{1 t}=g_{0} r_{t}+g_{1} r_{t-1}, \quad t=0,1, \ldots, T-1 .
$$

In contrast to $\tilde{w}_{1}$, the scaling coefficients $\tilde{v}_{1}$ are based on local averages (of length two) of the original returns. By collecting both sets of coefficients into $\tilde{w}=\left(\tilde{w}_{1}, \tilde{v}_{1}\right)$, we have separated (or filtered) the high-frequency and low-frequency content from the original returns.

The wavelet coefficients $\tilde{w}_{1}$ are associated with the high-frequency (rapidly oscillating) content of the returns $r_{t}$. From fundamental properties of the spectral density function of a stationary process, the spectrum of $r_{t}$ spans all frequencies $f$ between zero and 1/2 cycles per time unit (e.g., a second, an hour or a day). The wavelet coefficients $\tilde{w}_{1}$ are associated with the upper half of frequencies of $r_{t}$, $1 / 4<f \leq 1 / 2$. The scaling coefficients $\tilde{v}_{1}$ are associated with the lower half of frequencies, $0 \leq f \leq 1 / 4$. Thus, all the frequencies in the spectrum of $r_{t}$ are contained in one of the two vectors from the wavelet transform. The coefficients $\left(\tilde{w}_{1}, \tilde{w}_{1}\right)$ are an alternative representation of $r_{t}$ associated with differences and averages at two distinct 
scales. We can apply the convolutions in Eqs. (12) and (13) to the scaling coefficients $\tilde{v}_{1}$ (instead of the returns $r_{t}$ ) in order to produce the wavelet coefficients $\tilde{w}_{2}$, associated with frequencies $1 / 8<f \leq 1 / 4$, and scaling coefficients $\tilde{v}_{2}$ associated with the frequency interval $0 \leq f<1 / 8$. This procedure may be repeated on each subsequent vector of scaling coefficients up to the level $J \leq \log _{2} T$. The final collection of wavelet and scaling coefficients may be organized into the vector $\tilde{w}=\left(\tilde{w}_{1}, \tilde{w}_{2}, \ldots, \tilde{w}_{J}, \tilde{v}_{J}\right)$. The wavelet coefficients from level $j=1,2, \ldots, J$ are associated with the frequency interval $1 / 2^{(j+1)}<f \leq 1 / 2^{j}$ while the remaining scaling coefficients $\tilde{v}_{J}$ are associated with the remaining frequencies $0 \leq f \leq 1 / 2^{(j+1)}$. The procedure of filtering output from a previous filtering operation is known as a filter cascade and allows one to relate the final filtered series to the original series via a single filter. This topic will not be introduced here, but the interested reader is invited to consult Gençay et al. (2001a).

The interpretation of wavelet coefficients as the difference of averages formed using $2^{j-1}$ returns is natural when using the Haar wavelet filter. Likewise, scaling coefficients are a simple average of $2^{j}$ returns. When decomposing $r_{t}$ using the wavelet transform, we are actually separating layers of information associated with different time scales that increase with the level of the transform. Although beyond the scope of this paper, longer wavelet filters ${ }^{8}$ also retain this interpretation as the difference of weighted averages. After the wavelet coefficient vector is associated with changes at the longest time scale, the remaining information (frequencies) is captured in the scaling coefficients.

\subsection{Wavelet variance and covariance}

An important characteristic of the wavelet transform is its ability to decompose (analyze) the variance of a time series. When discussing the wavelet transform in the previous section, we pointed out that a vector of wavelet coefficients is associated with changes at a particular scale. This means that each wavelet coefficient was constructed using a difference of two (weighted) averages. Applying the wavelet transform to a return series produces a decomposition on a scale-by-scale basis.

If we assume that dependence structure of our return $r_{m t}$ is independent of time (this is true for a stationary time series), then we may define the time-independent wavelet variance, or just the wavelet variance, of asset $m$ associated with level $j$ to be $\sigma_{m j}^{2}=\operatorname{Var}\left(\tilde{w}_{m j}\right)$. That is, the level $j$ wavelet variance is simply the variance of the wavelet coefficients at level $j$ and may be estimated using wavelet coefficients not affected by the boundary (Gençay et al., 2001a, Ch. 7).

Let $r_{m t}$ and $r_{n t}$ be the return from two distinct assets $m$ and $n$. We obtain a wavelet decomposition for each asset by applying the wavelet transform to $r_{m t}$ and $r_{n t}$ individually yielding the wavelet coefficient vectors $\tilde{w}_{m}$ and $\tilde{w}_{n}$, respectively. The wavelet covariance between $r_{m t}$ and $r_{n t}$ for level $j$ is given by $\operatorname{Cov}\left(\tilde{w}_{m j}, \tilde{w}_{n j}\right)$ and unbiased estimation is provided in Gençay et al. (2001a, Ch. 7). Notice that the squared wavelet coefficients from this decomposition at each scale capture a certain

\footnotetext{
${ }^{8}$ The compactly supported wavelet filters of Daubechies (1992) have been widely used.
} 
part of the energy in returns and enable us to decompose the total energy across scales. In other words, covariances and variances might be significantly different at certain scales, implying different betas at different scales.

\section{Empirical results}

\subsection{United States}

Our data set consists of all the stocks listed in the S\&P 500 index between January 1, 1973 and November 1, 2000 for portfolio construction purposes. The S\&P 500 index is taken to be the corresponding market portfolio. The risk-free rate of return $r_{0 t}$ is assumed to be the daily rate of return from the 10-Year Treasury bill. ${ }^{9}$ The sample size is 7263 market days or roughly 28 years.

The daily return of each stock is calculated as the log price difference $r_{i t}=\log P_{i t}-\log P_{i t-1}$, where $P_{i t}$ is the price of asset $i$ at day $t$. The market return $r_{m t}$ is taken as the $\log$ difference of the S\&P 500 index $r_{m t}=\log S_{t}-\log S_{t-1}$, where $S_{t}$ is the index value at day $t$. During the entire sample period, the beta of each individual stock is calculated from a one year subsample using the wavelet beta estimator $\beta_{i j}^{w}$ utilizing the $\operatorname{LA}(8)$ wavelet filter ${ }^{10} \beta_{i j}^{w}=\left[\operatorname{Cov}\left(\tilde{w}_{m j}, \tilde{w}_{i j}\right)\right] / \sigma_{m j}^{2}$, for scales $j=1,2, \ldots, 6$, where $\sigma_{m j}^{2}=\operatorname{Var}\left(\tilde{w}_{m j}\right)$ is the wavelet variance of the market premium (the difference between market return $r_{m t}$ and the risk-free return $r_{0 t}$, see Eq. (9)) at the wavelet scale $j$ and $\operatorname{Cov}\left(\tilde{w}_{m j}, \tilde{w}_{i j}\right)$ is the wavelet covariance at wavelet scale $j$ between the individual stock premium (the difference between return $r_{i t}$ and the riskfree return $r_{0 t}$ ) and the market premium. Since we employ daily data in our analysis, wavelet scales are such that scale 1 is associated with $2-4$ day dynamics, scale 2 with 4-8 day dynamics, scale 3 with 8-16 day dynamics, scale 4 with 16-32 day dynamics, scale 5 with 32-64 day dynamics and scale 6 with 64-128 day dynamics. Since the portfolio updating is carried out every year, scale 6 is the highest scale at which we can calculate the beta of each stock because scale 7 corresponds to 128-256 day dynamics (approximately one year).

The stocks are ranked at each scale according to their estimated wavelet betas for every year in the sample period. From these rankings, 10 (and 15) portfolios with an equal number of stocks are constructed such that the first portfolio consists of stocks with the lowest betas while the final portfolio contains the stocks with the highest betas. The return from each portfolio (stocks are equally weighted in each portfolio) during the following year is calculated and the portfolio beta with the corresponding average return is retained. This process of updating portfolios every year according to beta sizes and calculating the average return from each portfolio for the next year is repeated for the entire sample. ${ }^{11}$

\footnotetext{
${ }^{9}$ The data source for individual stocks and the S\&P 500 index is Datastream. The 10-Year Treasury bill (constant maturity rate) is obtained from the H.15 Release, Federal Reserve Board of Governors. Days are defined as market days, not calendar days.

${ }^{10}$ We denote the Daubechies least asymmetric wavelet filter of length $L$ via $\operatorname{LA}(L)$.

${ }^{11}$ See Reinganum (1981) for a similar approach to beta estimation and testing the CAPM.
} 
When the entire sample period is covered, we have average betas for 10 (and 15) portfolios, from lowest beta portfolios to the largest beta portfolios, and corresponding average returns at each wavelet scale. If the CAPM is valid, we expect a positive relationship between the average beta of each portfolio and the corresponding average return. In other words, we expect that as the average beta increases, the average return increases as well. Fig. 1 plots average daily portfolio returns (vertical axis) versus corresponding average portfolio betas at different wavelet scales. The returns are expressed as a yearly compound rate in percent. Visual inspection of Fig. 1 reveals that there is a positive relationship between the average betas of portfolios and average returns at every scale. Furthermore, as the scale increases from low (Fig. 1a) to high (Fig. 1f), the slope between the beta and the return increases. In other words, the plots indicate that the well-known smiling face in many instances is reduced as the scale increases. This observation indicates that a seemingly nonlinear relationship between risk and return may be a scale specific phenomenon. Further study on this issue is required by considering capitalization weighted portfolios to capture possible size effects in multiscale beta estimation.

Table 1 reports the OLS estimate of the regression coefficient of average portfolio return (dependent variable) versus average portfolio betas (independent variable) at different scales for both 10 and 15 portfolios. The OLS estimate of average return versus average portfolio betas from the raw data is also reported for comparison. The results in Table 1 show that the positive relationship between the beta of each portfolio and the corresponding average return is significant at all wavelet scales. Notice that the magnitude of the regression coefficient increases as wavelet scale increases. For example, an increase in portfolio beta from $\beta=1$ to $\beta=2$ results in (annual compound) a $4.8 \%$ increase in the daily portfolio return at the first wavelet scale, while the same increase in portfolio beta results in (annual compound) a $15.8 \%$ increase at the sixth wavelet scale. ${ }^{12}$ We further notice that scales 2 and 5 stand out from others with higher $R^{2}$ s and lower statistical significance levels of the regression slope. There is no obvious reason for this difference; however, a strong possibility is that weekly seasonality (captured primarily by the second wavelet scale) might be causing a stronger relationship between the average return and beta at these scales.

According to the CAPM, if the return-beta relation is valid then the OLS estimate of the regression coefficient of average portfolio return (dependent variable) versus average portfolio betas (independent variable) must be equal to the market risk premium. The estimated slopes at scales 2 and 3 approximate this premium, implying that the return-beta relation is a multiscale phenomenon. The estimated slopes at the lowest scale underestimates the market premium. In other words, the predictions of the CAPM are more relevant for investors with medium-to long-run horizons as compared to those with short time horizons.

\footnotetext{
${ }^{12}$ The estimated regression coefficient in Table 1 is 0.000181 at scale one (for both 10 and 15 portfolios). This means that a one unit increase in portfolio beta (from $\beta=1$ to $\beta=2$ ) results in 0.000181 unit increase in average daily return. Assuming 260 business days, the corresponding annual compound increase is $4.8 \%$ since $(1+0.000181)^{260}=1.0482$.
} 
a

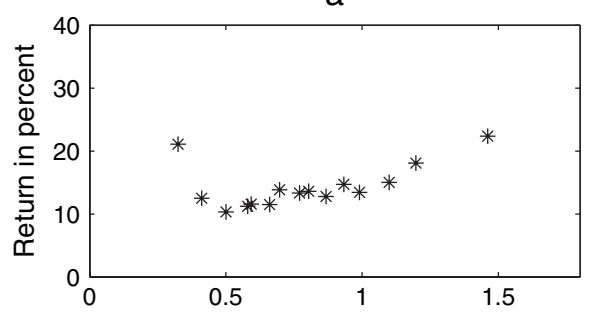

C

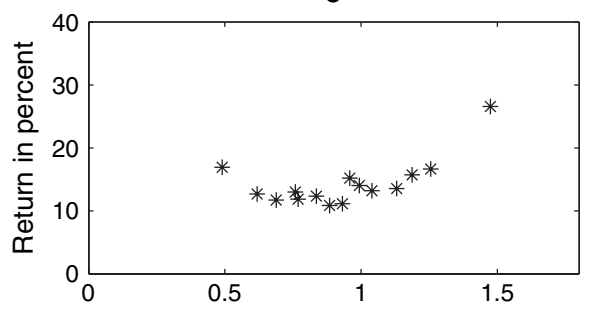

e

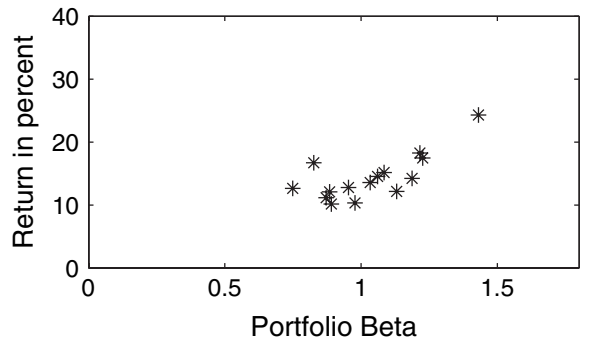

$\mathrm{b}$

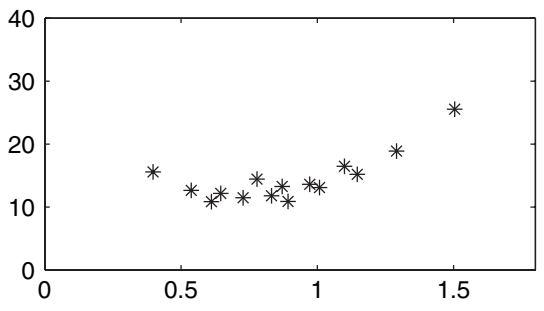

d

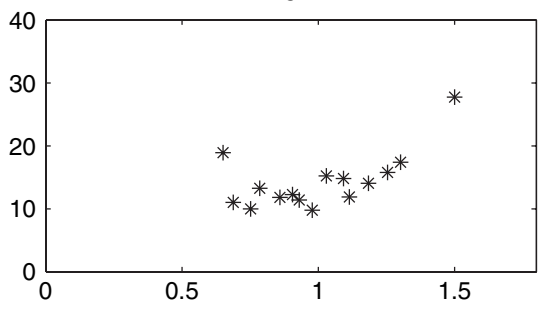

f

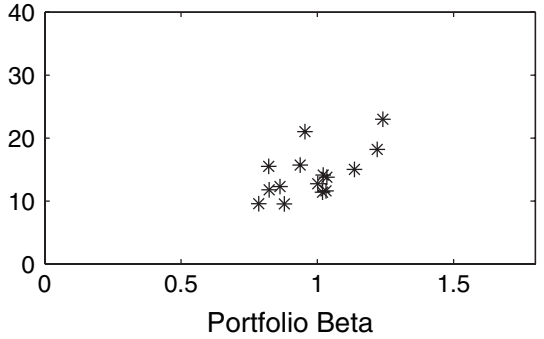

Fig. 1. Average daily portfolio returns (vertical axis) versus corresponding average portfolio betas at different wavelet scales. The returns are expressed as yearly compound rate in percent. The wavelet scales are such that (a) scale 1: 2-4 day periods, (b) scale 2: 4-8 day periods, (c) scale 3: 8-16 day periods, (d) scale 4: 16-32 day periods, (e) scale 5: 32-64 day periods and (f) scale 6: 64-128 day periods. Notice that as the scale increases from low (a) to high (f), the slope between the beta and the return becomes larger and it also better approximates the market risk premium.

\subsection{Germany}

A comprehensive example of estimating the systematic risk in a multiscale framework was presented in the previous section. The example utilized daily stock market data from the US economy, covering approximately 28 years. The estimated wavelet betas and average returns were calculated for different portfolios every year. In this section, we utilize a shorter sample period from another economy, Germany. Our purpose is to show that the wavelet multiscale approach to systematic risk estimation is robust and provides useful insight about the market developments even for shorter time periods. 
Table 1

The OLS estimates of average portfolio return (dependent variable) versus average portfolio beta (independent variable) at different scales

\begin{tabular}{|c|c|c|c|c|c|c|}
\hline & \multicolumn{3}{|l|}{10 Portfolios } & \multicolumn{3}{|c|}{15 Portfolios } \\
\hline & Constant & Slope & $R^{2}$ & Constant & Slope & $R^{2}$ \\
\hline Scale 1 & $0.0376^{* * *}$ & $0.0181 *$ & 0.16 & $0.037 * * *$ & $0.0181 *$ & 0.17 \\
\hline Scale 2 & $0.026^{* *}$ & $0.0293 * * *$ & 0.49 & $0.024 * * *$ & $0.0303 * * *$ & 0.48 \\
\hline Scale 3 & $0.025^{* *}$ & $0.0287 * *$ & 0.35 & $0.024 * *$ & $0.0293 * *$ & 0.31 \\
\hline Scale 4 & 0.016 & $0.0358 * *$ & 0.34 & 0.014 & $0.0370 * *$ & 0.32 \\
\hline Scale 5 & 0.004 & $0.0461 * * *$ & 0.52 & 0.001 & $0.0486 * * *$ & 0.49 \\
\hline Scale 6 & -0.004 & $0.0565^{* *}$ & 0.30 & -0.004 & $0.0560 * *$ & 0.31 \\
\hline Raw & $0.025^{* *}$ & $0.306^{* *}$ & 0.52 & $0.024 * *$ & $0.315^{* *}$ & 0.51 \\
\hline
\end{tabular}

The raw data is also reported for comparison. The wavelet scales for (a)-(f) are defined as in Fig. 1. The results are obtained from 10 different portfolios (left) and 15 different portfolios (right) constructed according to the beta ranking of stocks. Both slope and intercept are multiplied by 100 for reporting purposes. One star $\left(^{*}\right)$ indicates that the coefficient is significant at the $10 \%$ level of significance, two stars $(* *)$ at $5 \%$, and three stars $(* * *)$ at $1 \%$.

Our data set from Germany consists of all the stocks, except three, included in the Xetra DAX Index (DAX30) between January 3, 2000 and December 28, 2001. ${ }^{13}$ The sample size is 499 days. The daily return of each stock is calculated as the log price difference $r_{i t}=\log P_{i t}-\log P_{i t-1}$, where $P_{i t}$ is the price of asset $i$ at day $t$. The market return, $r_{m t}$ is assumed to be the log difference of the DAX30 index $r_{m t}=\log D_{t}-\log D_{t-1}$, where $D_{t}$ is the index value at day $t$. The risk-free rate of return $r_{0 t}$ is assumed to be the daily EURIBOR. ${ }^{14}$ The beta of each individual stock for the entire sample period is calculated using the wavelet beta estimator $\beta_{i j}^{w}$ from the same $\mathrm{LA}(8)$ wavelet filter as before.

Fig. 3 plots average daily stock returns (vertical axis) versus corresponding stock betas at different wavelet scales in Germany. The returns are expressed in daily percent. The wavelet scales are such that scale 1 is associated with 2-4 day dynamics, scale 2 is associated with 4-8 day dynamics and so on. As previously mentioned, if the beta-return relation is valid then the slope from the regression of the stock return on the stock beta must be equal to the average market premium $E\left(r_{m t}-r_{0 t}\right)$ during the sampling period. The average daily market premium, defined as the sample average of $r_{m t}-r_{0 t}$ is -0.00066 and corresponds to a yearly (compound) rate of return of $16 \%$. The OLS estimates of the slopes in Fig. 3 indicate that the average market risk premium is underestimated in the first two scales $(-24.5 \%$ and $-20.5 \%$, respectively). The estimated slope at the third scale implies an average market premium of $-18.5 \%$ which is very close to the realized average market premium. At

\footnotetext{
${ }^{13}$ Infineon Tech., Henkel Kgaa., and Deutsche Post are excluded because of missing prices for certain days during the sample period.

${ }^{14}$ The data source for individual stocks and the DAX30 is http://finance.yahoo.com. Stock prices are adjusted for dividends and splits. The daily EURIBOR is taken from http://www.euribor.org. EURIBOR (Euro Interbank Offered Rate) is the rate at which euro interbank term deposits within the euro zone are offered by one prime bank to another.
} 
higher scales, the market premium is overestimated again. We conclude that the third scale (capturing dynamics with a period of 8-16 days) explains the return-beta relationship much better than other scales during the sample period.

\subsection{The United Kingdom (UK)}

In the German example, we utilized a shorter time period and assumed that the market return could be captured by a popular stock market index, the DAX30. A multiscale analysis of stocks included in the DAX30 was equivalent to analyzing the entire market. Although it is a common approach in applied work, the assumption of a stock market index representing the market and its components is rarely valid in

a

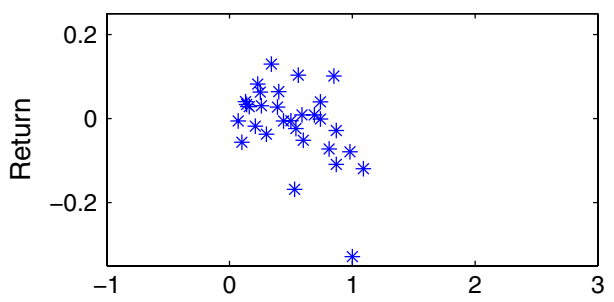

C

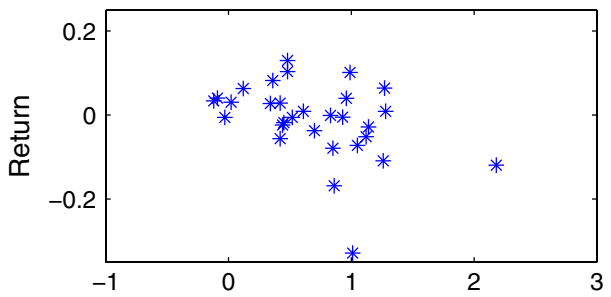

e

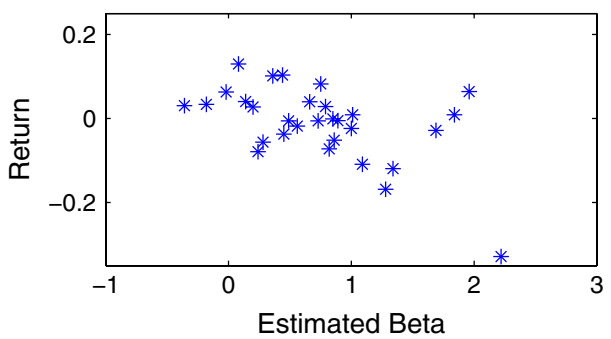

b

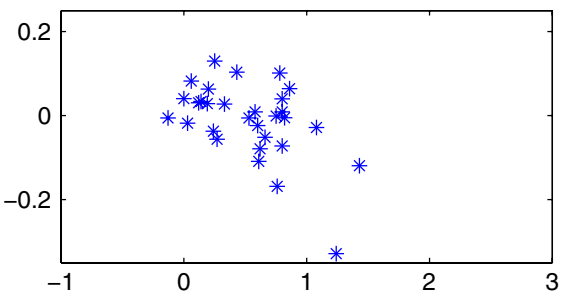

d

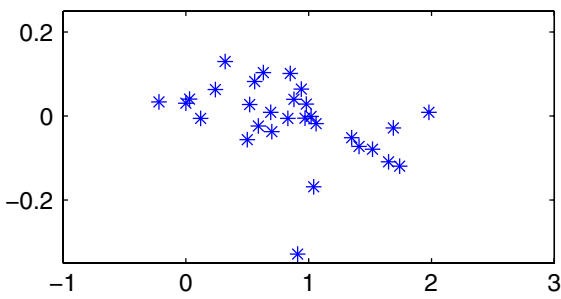

f

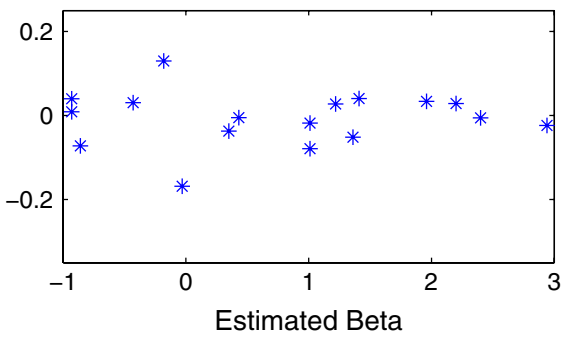

Fig. 2. Average daily stock returns (vertical axis) versus corresponding average stock betas at different wavelet scales in the UK. The returns are expressed in daily percent. The wavelet scales for (a)-(f) are defined as in Fig. 1. As the scale increases from low (a) to high (f), the slope between the beta and the return gets larger and it better approximates the market premium, except at the sixth scale. 
a

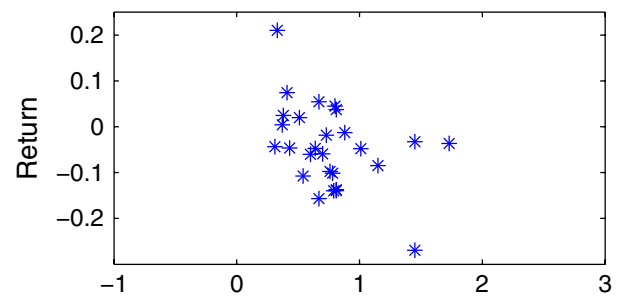

C

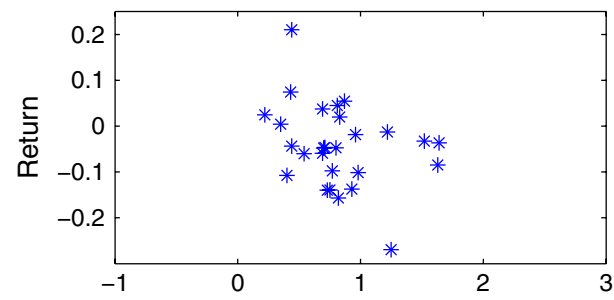

e

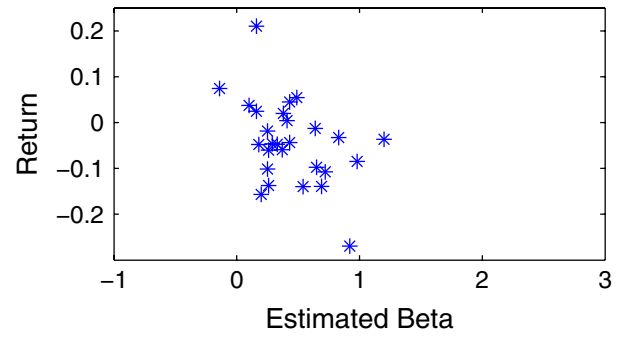

b

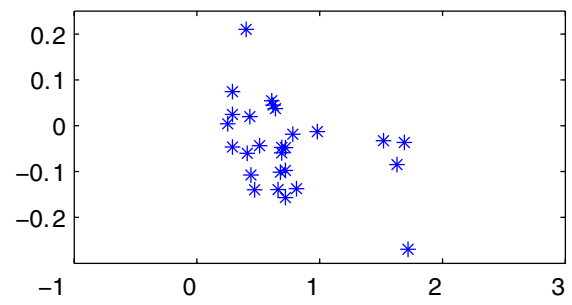

d

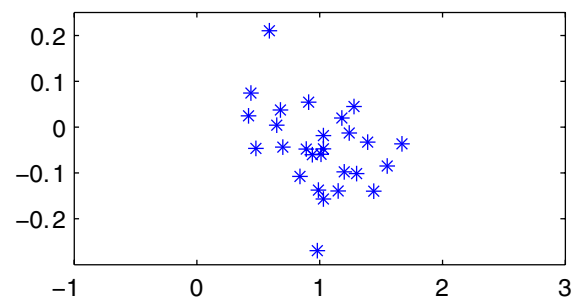

f

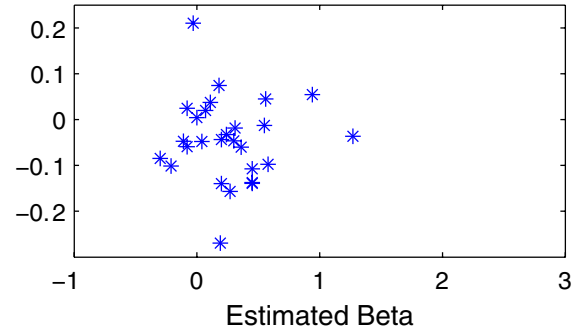

Fig. 3. Average daily stock returns (vertical axis) versus corresponding stock betas at different wavelet scales in Germany. The returns are expressed in daily percent. The wavelet scales for (a)-(f) are defined as in Fig. 1. Notice that as the scale increases from low (a) to high (f), the slope between the beta and the return becomes larger and it better approximates the market premium.

practice, and the robustness of our analysis could benefit from being tested in a more realistic framework.

Our data for the UK consist of a random sample of thirty stocks included in the Financial Times Stock Index (FTSE100) between January 4, 2000 and December 28, 2001. ${ }^{15}$ The corresponding market portfolio is taken to be the FTSE100. The riskfree rate of return $r_{0 t}$ is assumed to be the daily rate of return from the 1-month UK

\footnotetext{
15 The following stocks were chosen randomly among the FTSE100 stocks: Anglo American, Boots Co., Northern Rock, BP, Shell, Schroders, Prudential, Scottish Power, Cadbury Schweppes, Smith \& Nephew, Next, BAE Systems, Severn Trent, Marks \& Sp., Six Continents, Granada, Lloyds, Scot \& New Castle, Dixons Group, Canary Wharf, Amersham, British Sky B., Old Mutual, Aliance \& Leicense, BT Group, Hays, Allied Domesq., HBOS, Shire Pharm., Abbey National.
} 
treasury bill middle rate. ${ }^{16}$ The sample size is 491 days. With this example, we examine a situation in which a researcher captures only part of the market.

The daily return of each stock and the FTSE100 is calculated as the log price difference. During the entire sample period, the beta of each individual stock is calculated using the wavelet beta estimator $\beta_{i j}^{w}$ from the $\mathrm{LA}(8)$ wavelet filter. Fig. 2 plots average daily stock returns (vertical axis) versus corresponding stock betas at different wavelet scales in the UK. The returns are expressed in daily percent. The wavelet scales are such that scale 1 is associated with $2-4$ day dynamics, scale 2 is associated with 4-8 day dynamics and so on. The yearly market premium (compound) rate of return during the sample period in the UK is $15.6 \%$, a figure very close to the German average. The OLS estimates of the slopes in Fig. 3 indicate that the average market risk premium is underestimated in the first two scales $(-31.3 \%$ and $-27 \%$, respectively). The estimated slope at the third scale implies an average market premium of $-17.5 \%$, the fourth scale $-16.2 \%$ and the fifth scale $-18 \%$. Once again, the return-beta relationship is captured at higher scales much better than at the lower wavelet scales. These findings enforce our earlier conclusion that the return-beta relationship is a multiscale phenomenon and longer time scales are more relevant in explaining the relationship when compared to short time scales.

\section{Conclusions}

In this paper we propose a new approach for estimating the systematic risk or the beta of an asset in a capital asset pricing model (CAPM). The proposed method is based on a wavelet multiscaling approach that decomposes a given time series on a scale-by-scale basis. At each scale, the wavelet variance of the market return and the wavelet covariance between the market return and a portfolio are calculated to obtain an estimate of the portfolio's systematic risk (beta). The empirical results show that the relationship between the return of a portfolio and its beta becomes stronger as the scale increases. That is, predictions of the CAPM are more relevant at medium- to long-run horizons as compared to short time horizons.

\section{Acknowledgements}

This work was partially completed while F. Selçuk was a visiting associate professor at Colorado College, Colorado Springs, CO. F. Selçuk greatly acknowledges financial support from the Colorado College Social Science Executive Division Research and Development Fund. R. Gençay gratefully acknowledges financial support from the Swiss National Science Foundation under NCCR-FINRISK, Natural Sciences and Engineering Research Council of Canada and the Social Sciences and Humanities Research Council of Canada. Support for B. Whitcher was

\footnotetext{
${ }^{16}$ Data source for individual stocks and the FTSE100 is http://finance.yahoo.com. Stock prices are adjusted for dividends and splits. The UK 1-month treasury bill middle rate is obtained from the Datastream.
} 
provided by the National Center for Atmospheric Research (NCAR) Geophysical Statistics Project, sponsored by the National Science Foundation (NSF) under Grants DMS98-15344 and DMS93-12686. We thank Abdurrahman Ulugülyağc1 for research assistance.

\section{References}

Bekaert, G., Harvey, C.R., 1995. Time-varying world market integration. Journal of Finance 50, $403-444$. Bekaert, G., Harvey, C.R., 1997. Emerging equity market volatility. Journal of Financial Economics 43, 29-78.

Bjornson, B., Kim, H.S., Lee, K., 1999. Low and high frequency macroeconomic forces in asset pricing. Quarterly Review of Economics and Finance 39, 77-100.

Black, F., 1972. Capital market equilibrium with restricted borrowing. Journal of Business 45, 444-454.

Black, F., Jensen, M., Scholes, M., 1972. Capital asset pricing model: some empirical tests. In: Jensen, M. (Ed.), Studies in the Theory of Capital Markets. Praeger, New York.

Blanchard, O.J., Fischer, S., 1989. Lectures on Macroeconomics. The MIT Press, Cambridge, MA.

Brailsford, T.J., Josev, T., 1997. The impact of return interval on the estimation of systematic risk. PacificBasin Finance Journal 5, 353-372.

Brailsford, T.J., Faff, R.W., 1997. Testing the conditional CAPM and the effect of intervaling: a note. Pacific-Basin Finance Journal 5, 527-537.

Campbell, J.Y., 2000. Asset pricing at the millennium. Journal of Finance 55, 1515-1567.

Cochrane, J.H., 1999. New facts in finance. Economic perspectives. Federal Reserve Bank of Chicago 23 , 59-78.

Cohen, K., Hawawini, G., Mayer, S., Schwartz, R., Whitcomb, D., 1986. The Microstructure of Securities Markets. Prentice-Hall, Sydney.

Daubechies, I., 1992. Ten Lectures on Wavelets. SIAM, Philadelphia, PA.

Fama, E.F., 1980. Stock returns, expected returns, and real activity. Journal of Finance 45, $1089-1107$.

Fama, E.F., 1981. Stock returns, real activity, inflation and money. American Economic Review 71, 545565.

Fama, E.F., MacBeth, J., 1973. Risk, return and equilibrium: empirical tests. Journal of Political Economy 71, 607-636.

Frankfurter, G., Leung, W., Brockman, W., 1994. Compounding period length and the market model. Journal of Economics and Business 46, 179-193.

Garcia, R., Ghysels, E., 1998. Structural change and asset pricing in emerging markets. Journal of International Money and Finance 17, 455-473.

Gençay, R., Selçuk, F., Whitcher, B., 2001a. An Introduction to Wavelets and Other Filtering Methods in Finance and Economics. Academic Press, San Diego.

Gençay, R., Selçuk, F., Whitcher, B., 2001b. Differentiating intraday seasonalities through wavelet multiscaling. Physica A 289, 543-556.

Gençay, R., Selçuk, F., Whitcher, B., 2001c. Scaling properties of foreign exchange volatility. Physica A 289, 249-266.

Handa, P., Kothari, S.P., Wasley, C., 1989. The relation between the return interval and betas: implications for the size effect. Journal of Financial Economics 23, 79-100.

Handa, P., Kothari, S.P., Wasley, C., 1993. Sensitivity of multivariate tests of the capital asset pricing to the return interval measurement. Journal of Finance 48, 15-43.

Harvey, C.R., 1989. Time-varying conditional covariances in tests of asset pricing models. Journal of Financial Economics 24, 289-317.

Harvey, C.R., 1991. The world price of covariance risk. Journal of Finance 46, 111-157.

Hawawini, G., 1983. Why beta shifts as the return interval changes. Financial Analysts 39, $73-77$.

Levhari, D., Levy, H., 1977. The capital asset pricing model and the investment horizon. Review of Economics and Statistics 59, 92-104. 
Lintner, J., 1965. The valuation of risky assets and the selection of risky investments in stock portfolios and capital budgets. Review of Economics and Statistics 47, 13-37.

Mallat, S., 1998. A Wavelet Tour of Signal Processing. Academic Press, San Diego.

Ramsey, J.B., 1999. The contribution of wavelets to the analysis of economic and financial data. Philosophical Transactions of the Royal Society of London A 357, 2593-2606.

Ramsey, J.B., Lampart, C., 1998a. The decomposition of economic relationships by time scale using wavelets: expenditure and income. Studies in Nonlinear Dynamics and Economics 3, 23-42.

Ramsey, J.B., Lampart, C., 1998b. Decomposition of economic relationships by timescale using wavelets: money and income. Macroeconomic Dynamics 2, 49-71.

Ramsey, J.B., Zhang, Z., 1997. The analysis of foreign exchange data using waveform dictionaries. Journal of Empirical Finance 4, 341-372.

Reinganum, M.R., 1981. A new empirical perspective on the CAPM. Journal of Financial and Quantitative Analysis 16, 439-462.

Scholes, M., Williams, J., 1977. Estimating betas from non-synchronous data. Journal of Financial Economics 5, 309-327.

Sharpe, W., 1964. Capital asset prices: a theory of market equilibrium under conditions of risk. Journal of Finance 19, 425-442. 